\title{
Cadmium, Cobalt, Lead and Zinc Levels in Soil and Edible Vegetables in Yala Urban Area of Cross River State, Nigeria
}

\author{
*AKPE, MA; UBUA, PU; ONYEBUENYI, IB
}

\author{
Department of Pure and Applied Chemistry, University Of Calabar, Calabar, Nigeria \\ *Corresponding Author Email: akomayeakpe2015@gmail.com
}

\begin{abstract}
The average level of cadmium $(\mathrm{Cd})$, cobalt $(\mathrm{Co})$, lead $(\mathrm{Pb})$ and zinc $(\mathrm{Zn})$ in the soil and edible vegetables samples collected randomly in Yala Urban Area of Cross River State was determined using flame Atomic Absorption Spectrometer. The samples were digested and analyzed for the metals level or concentration in Chemistry Laboratory, University of Calabar. The eight vegetables selected for the study were Amaranthus spp., Corchorus olitorius, Murraya koenigii, Ocimum grattissimum, Solanum melongena, Talinum triangulare, Telferia occidentalis and Vernonia amygdalina. The results indicated that the average level of the metals in the soil in $\mathrm{mgkg}^{-1}$ ranged from $(0.005-0.021)$ and $(0.004-0.019)$ in rainy and dry seasons respectively for Cadmium, $(0.162-0.475)$ and $(0.163-$ $0.472)$ in rainy and dry season respectively for Cobalt, and (0.434-1.030) and (0.432-1.027) in rainy and dry season respectively for Zinc. Also, the average level of the metals accumulated by the vegetables in $\mathrm{mgkg}^{-1}$ ranged from $(0.002-0.009)$ and (0.001- 0.007) in rainy and dry season respectively for Cadmium, (0.050-0.198) and (0.048-0.195) in rainy and dry season respectively for Cobalt, and (0.158-0.383) and (0.156-0.380) in rainy and dry season respectively for Zinc. The level of Lead in the soil or vegetables was not detected. The average level of metals accumulated by the vegetables and that present in the soil was in the order: Zinc $>$ Cobalt $>$ Cadmium $>$ Lead. These results revealed that there is no significant difference between the level of metals in the soil or that accumulated by the vegetables in rainy and dry seasons of the year. Also the level of metals accumulated by most of the vegetables was directly proportional to the amount present in the soil where they are planted. The Target Hazard Quotients of these metals was less than 1 . These results imply that the concentration of Cadmium, Cobalt, Zinc and Lead in the soil and vegetables were still low and within the permissible limits of World Health Organization. Thus, the consumption of the vegetables in the area may not pose any health risk for now.
\end{abstract}

DOI: https://dx.doi.org/10.4314/jasem.v24i5.16

Copyright: Copyright $(02020$ Akpe et al. This is an open access article distributed under the Creative Commons Attribution License (CCL), which permits unrestricted use, distribution, and reproduction in any medium, provided the original work is properly cited.

Dates: Received: 29 March 2020; Revised: 27 April 2020; Accepted: 18 May 2020

Keywords: Heavy metals, Concentration, Soil, Edible vegetables.

Cadmium, Cobalt, Lead and Zinc belongs to the transition metals. Due to their poisonous or toxic effect at high doses and their contamination of food plants and animals when present in the soil or water environments, they have recently attracted the attention of many researchers worldwide as food safety and quality is a matter of public interest. Also, increasing demands for food and its safety has drawn the attention of researchers to the health risk associated with consumption of contaminants in vegetables (Dmello, 2003). There is an increasing concern about the quality of foods in several parts of the world. The studies of toxicological and environmental hazards have spurred the interest in the determination of toxic elements in food. Food safety and quality determines its value or acceptability to consumers. As a result of this, researchers like Jackson and Alloway (1993) have stated from their study that application of residuals to soil introduces heavy metals into the soil. The cultivation of lands contaminated with heavy metals from industrial effluents, vehicular emissions and other anthropogenic activities have resulted in the growth of contaminated vegetables (Rattan et al., 2005). Obasi et al. ( 2012) have also studied heavy metals contamination of soil along Enugu-Port Harcourt expressway in Ngeria and reported mean concentration of $\mathrm{Cd}, \mathrm{Cr}, \mathrm{Cu}, \mathrm{Fe}, \mathrm{Mn}, \mathrm{Ni} \mathrm{Pb}$ and $\mathrm{Zn}$ ranging from 10.58 to $635 \mathrm{mg} / \mathrm{kg}$, with $\mathrm{Cd}, \mathrm{Fe}$ and $\mathrm{Pb}$ in decreasing order the most mobile and bioavailable to the environment. A study on the heavy metals contamination of soil and vegetables in sub-urban areas of Varanasi in India revealed that $\mathrm{Cr}, \mathrm{Cu}, \mathrm{Mn}, \mathrm{Ni}$ $\mathrm{Pb}$ and $\mathrm{Zn}$ except $\mathrm{Cd}$ were below $\mathrm{WHO}$ permissible limits for agricultural use (Kumar et al., 2007). Also, the assessment of heavy metals contamination of different vegetables grown in and about Urban areas of in a certain region in Iran have shown that the average level of $\mathrm{Pb}, \mathrm{Cu}, \mathrm{Cr}$ and $\mathrm{Cd}$ are a health hazard for human consumption according to Iran National Nutrition and Food Research Institute (Suruchi and Khanna, 2011). In Australia, Rahman et al. (2014) analyzed heavy metals in rice grown in Australia and those imported, and vegetables on sale and revealed that heavy metals levels in Australian grown rice were higher than those imported from Bangladesh and their levels in vegetables were higher than the Australian Standard maximum limits. Several other researchers have carried out studies on heavy metals in different parts of the world to ascertain their food and environment quality/safety. Cadmium is emitted to the air by mines, metal smelters and industries using cadmium compounds for alloys, batteries, pigments 
and in plastics, although many nations have stringent controls in place for such emissions (Harrison, 2001). Cobalt is used in many alloys (super alloys for parts in gas turbine aircraft engines, corrosion resistant alloys, high speed steels, cemented carbides), in magnets and magnetic recording media, as catalysts for the petroleum and chemical industries, as drying agents for paints and inks. Human exposure to Co takes place through air, drinking water and food (ATSDR, 2011). Food is one of the major sources of Lead exposure; others are air (mainly its dust emanating from petrol) and drinking water. Plant food may be contaminated with Lead through its uptake from ambient air and soil; animals may then ingest the Lead-contaminated vegetation. In humans, its ingestion may arise from eating Lead-contaminated vegetation or animal foods (Ming-Ho, 2005). Zinc is the most abundant element occurs in the earth's crust and is used mostly in the manufacture of communications equipment and instruments (Emsley, 2001). It is also used in making alloys like Brass. Thus, most metal find their way into the ecosystem or food chain either by natural occurrence, their mining or extraction and their uses or applications. Halwell (2007) have reported that the nutritional value of vegetables depends on the growing method and the quality of the soil because when vegetables are grown in contaminated soils, like those polluted with heavy metals; their nutritional value will be depreciated as pollutants from the soil will be accumulated by the vegetables. Thus, vegetables should not be planted on soils contaminated with hazardous waste like heavy metals because they are nutritionally and medicinally valuable. Besides, the health of humans can be affected negatively when they consume these vegetables and accumulate these toxic substances in high doses. For instance, cadmium in high doses causes adverse effect on kidney, liver, bones, immune system and chronic poisoning (Ndukwu et al., 2008). Children are more sensitive to the effects of lead than adults. Most heavy metals in high doses can possibly cause disruption of or interference in endocrine system (Alvarez-Ayuso et al., 2011), phyto/cytotoxicity (Tan and Xiao, 2012) and dysfunction of the mitochondria (Fujimaki et al., 2004) among other health problems. Thus, cobalt and zinc are not exempted in high doses. Moreover, the heavy metals, viz; cadmium, lead and mercury are considered as strict and toxic contaminants for living beings, even at very lower concentrations (Salama et al., 2005 and Dauguet et al., 2011). The aim of this study is to determine the level of $\mathrm{Cd}, \mathrm{Co}, \mathrm{Pb}$ and $\mathrm{Zn}$ in the soil and edible vegetables in Yala (the study area) and ascertain the soil and vegetable quality with respect to their pollution.

\section{MATERIALS AND METHODS}

Description of Study Area: Yala urban area is characterized with low land, plains, some swamps and hills. The soil is well drain sandy loam in texture, which makes it suitable for agriculture. It has population of about 115 thousand people. Besides, the people engaged in subsistence and commercial farming, growing rice, cassava, yam in large quantities as well as vegetables for consumption as food and medicine. This often results in the use of insecticides, herbicides and other agrochemicals. By its location, it is a link to the eastern and northern part of the country and sometimes experience heavy vehicular traffic. In addition, its major urban centre; Okpoma and its neighbourhood Okuku where Cross River State University of Technology mini campus is located have business centres, auto-mechanic workshops, and State and Local Government institutions among other urban features. Moreover, 'the inhabitants plant vegetables in old waste dump sites at their backyards with a view to tap the compost manure for good yield even though wastes were indiscriminately disposed in these sites' (Akpe et al., 2019). All these features together with erosion during the rainy season make heavy metal contamination of the area inevitable. Hence, there is need to assess the edible vegetables and soil quality with respect to heavy metals pollution, and also evaluate the possible health risk related to their consumption.

Sampling and sample pre-treatment: 40 soil samples and vegetables (with 5 of each vegetable) were collected randomly at different locations within Yala urban area at a distance of about $1 \mathrm{~km}$ apart. The vegetables were grown or planted in gardens by the inhabitants of the area at their backyards or premises at old domestic waste dumpsites where wastes were disposed indiscriminately in order to tap the compost manure for good yield. The soil samples were collected at the root level of the vegetables at the depth of about 12 to $15 \mathrm{~cm}$, using a hand trowel. At the same time, a handful of the edible vegetables were collected and wrapped separately with identification labels, and taken to the laboratory for further analysis. The edible vegetables considered for this study include: Amaranthus spp (Green vegetable), Corchorus olitorius (Ewedu), Murraya koeningii (Curry leaf), Ocimium grattissimum (scent leaf), Solanum melongena (eggplant leaf), Telfairia occidentalis (pumpkin), Talinum triangulare (water leaf) and Vernonia amygdalina (Bitter leaf). They are commonly used for food and medicinal purposes in the area. The samples were collected between January and March for the dry season and between July and September for the rainy season of 2019. The vegetable samples were washed with distilled water and ovendried at $90{ }^{\circ} \mathrm{C}$ for about 3 hours. Each dried sample was ground into powder, sieved with a $0.3 \mathrm{~mm}$ sieve and stored in a labeled plastic jar with cap. The soil sampled was also oven-dried, ground into powder and homogenized using pestle and mortar, sieved and store in labeled plastic jars separately.

Digestion of samples: vegetable samples were digested as follows: $2 \mathrm{~g}$ of homogenised and sieved 
powder of each vegetable was transferred into a clean dry round-bottomed flask and digested using a mixture of concentrated acids namely; $15 \mathrm{~mL}$ of $\mathrm{HCl}, 10 \mathrm{~mL}$ of $\mathrm{HNO}_{3}, 5 \mathrm{~mL}$ of $\mathrm{H}_{2} \mathrm{SO}_{4}$ and $2 \mathrm{~mL}$ of $\mathrm{H}_{2} \mathrm{O}_{2}$, at about $100{ }^{\circ} \mathrm{C}$ on a hot plate for about three hours in a fume cupboard. Each digest was allowed to cool and deionized water was added to the digest and made up to $100 \mathrm{~mL}$ in a volumetric flask. The solution was stirred and filtered to obtain the filtrate ready for AAS analysis of heavy metals. In a similar way, the soil samples were digested following the procedure of one of the methods of the Association of Official Analytical Chemists (AOAC) as reported by Akan et al. (2010) thus: ' $2.0 \mathrm{~g}$ of each soil sample powder was weighed into an acid washed beaker. $20 \mathrm{~mL}$ of aqua regia (mixture of $\mathrm{HCl}$ and $\mathrm{HNO}_{3}$, in the ratio 3:1) was added to the sample in the beaker. The beaker was covered with a clean dry watch glass and heated at 90 ${ }^{0} \mathrm{c}$ for about 2 hours; the beaker was removed, allowed to cool, washed together with the watch glass using deionized water into a volumetric flask and made-up to $100 \mathrm{~mL}$ solution. The solution was filtered and supernatant liquid solution was used for heavy metal analysis.'

Measurement of $p H: 20 \mathrm{~g}$ of oven-dried soil samples were weighed into a $50 \mathrm{~mL}$ beaker and $20 \mathrm{~mL}$ of distilled water was added and the $\mathrm{pH}$ of the soil samples was determined using a $\mathrm{pH}$ meter and the results were recorded.

Element Analysis: the soil and vegetable samples were analyzed for $\mathrm{Cr}, \mathrm{Fe}, \mathrm{Hg}$ and $\mathrm{Ni}$ using a VGP 210 BUCK Scientific Model of flame Atomic Absorption Spectrometer (AAS) at the following wavelengths: $\mathrm{Cd}$ $(228.9 \mathrm{~nm}), \mathrm{Co}(240.7 \mathrm{~nm}), \mathrm{Pb}(283.3 \mathrm{~nm})$ and $\mathrm{Zn}$ (213.1 nm).

Calculations: The Target Hazard Quotient which is the ratio of the body intake dose of a pollutant to the reference dose was calculated thus:

$$
T H Q=\frac{D I V x C m}{R f D x B}
$$

Where DIV is the daily intake of vegetable in $\mathrm{kg} / \mathrm{day}$, $\mathrm{Cm}$ is the concentration of pollutant (heavy metal) in the vegetable in $\mathrm{mgkg}^{-1}$, B is the average body weight of humans in $\mathrm{kg}$, while RfD is the oral reference dose of the pollutant permissible and it is fixed by United States Environmental Protection Agency (US-EPA). Note: B is assumed by US-EPA to be $70 \mathrm{~kg}$ for men and $60 \mathrm{~kg}$ for women. For this study, $65 \mathrm{~kg}$ (the average of $70 \mathrm{~kg}$ and $60 \mathrm{~kg}$ ) was used for all adults, while the DIV was assumed to be $100 \mathrm{~g}(0.1 \mathrm{~kg} /$ day $)$ per day. In some countries or places, up to 150 or $200 \mathrm{~g}$ per day has been assumed especially for vegetarians. From the formula, THQ is a dimensionless parameter or ratio. According to US-EPA through Integrated Risk Information System-database IRIS (2011), 'if THQ is less than $1(\mathrm{THQ}<1)$, it shows that there is no potential health risk associated with the pollutant. But if $\mathrm{THQ}>1$, there is a health risk associated with the pollutant (heavy metal) at that moment.' The RfD values for $\mathrm{Cd}, \mathrm{Co}, \mathrm{Pb}$ and $\mathrm{Zn}$ from IRIS are $0.001,0.1$, 0.0035 and $0.3 \mathrm{mgkg}^{-1}$ respectively IRIS (2011).

Statistical Analysis: The data collected was analyzed using SPSS version 20. The data were expressed in terms of descriptive statistics and figures were presented with mean values of triplicates. Significance test was also computed using paired t-test at $\mathrm{P}<0.05$ for dry and rainy season data in order to check whether there was any significant difference.

\section{RESULTS AND DISCUSSION}

The mean heavy metal concentration in $\mathrm{mgkg}^{-1}$ (dry weight) in the soil and vegetables during the rainy and dry season have been presented in Tables 1 and 2 respectively, while the Target Hazard Quotients of the metals have been presented in Tables 3 and 4 for the both seasons.

$p H$ : It ranged from 4.2- 6.8 and 4.3- 6.7 in rainy and dry seasons respectively for all soil samples. The results in Tables 1 and 2 above indicated that the average level of the metals in the soil in $\mathrm{mgkg}^{-1}$ ranged from (0.005-0.021) and (0.004-0.019) in rainy and dry seasons respectively for $\mathrm{Cd},(0.162-0.475)$ and $(0.163-$ 0.472 ) in rainy and dry season respectively for $\mathrm{Co}$, and (0.434-1.030) and (0.432-1.027) in rainy and dry season respectively for $\mathrm{Zn}$. Also, the average level of the metals accumulated by the vegetables in $\mathrm{mgkg}^{-1}$ ranged from (0.002-0.009) and (0.001-0.007) in rainy and dry season respectively for $\mathrm{Cd},(0.050-0.198)$ and $(0.048-0.195)$ in rainy and dry season respectively for $\mathrm{Co}$, and (0.158-0.383) and (0.156-0.380) in rainy and dry season respectively for $\mathrm{Zn}$. The level of Lead $(\mathrm{Pb})$ in the soil or vegetables was not detected. The average level of metals accumulated by the vegetables and that present in the soil was in the order: $\mathrm{Zn}>\mathrm{Co}>\mathrm{Cd}>$ $\mathrm{Pd}$. The results also revealed that there is no significant difference between the level of the metals in the soil and vegetables for both seasons, suggesting that the source of these metals may not be from air pollution sources such as vehicular emissions or irrigation water sources used in dry season. Therefore, the source may be from indiscriminate disposal of waste containing these metals, leaching from auto-mechanic workshops etc.

The accumulation of these metals by vegetables depends on the amount of metal in the soil, its chemical form, the $\mathrm{pH}$ of the soil, its porosity which could determine their availability for the vegetables or plants. 'The chemical nature of Zinc and its interaction with other elements or substances in the soil for instance determines its availability in the soil for vegetables or plants to accumulate (Shuman, 1991 and Kiekens, 1990). 
Table 1: Average level of $\mathrm{Cd}, \mathrm{Co}, \mathrm{Pb}$ and $\mathrm{Zn}$ in $\mathrm{mgkg}^{-1}$ (dry weight) in the soil and vegetables during the rainy season in Yala urban area.

\begin{tabular}{lllll}
\hline Vegetable & Cd & Co & Pb & Zn \\
\hline Amarathus spp. & $0.004 \pm 0.002$ & $0.175 \pm 0.054$ & ND & $0.206 \pm 0.094$ \\
Soil & $0.010 \pm 0.003$ & $0.424 \pm 0.067$ & ND & $0.434 \pm 0.106$ \\
C. olitorius & $0.009 \pm 0.002$ & $0.198 \pm 0.075$ & ND & $0.220 \pm 0.091$ \\
Soil & $0.021 \pm 0.004$ & $0.457 \pm 0.047$ & ND & $0.909 \pm 0.102$ \\
M. koenigii & $0.007 \pm 0.003$ & $0.050 \pm 0.015$ & ND & $0.237 \pm 0.063$ \\
Soil & $0.016 \pm 0.003$ & $0.162 \pm 0.013$ & ND & $0.737 \pm 0.073$ \\
O. gratissimum & $0.002 \pm 0.001$ & $0.170 \pm 0.036$ & ND & $0.184 \pm 0.081$ \\
Soil & $0.007 \pm 0.002$ & $0.405 \pm 0.027$ & ND & $0.551 \pm 0.115$ \\
S. melongena & $0.007 \pm 0.003$ & $0.148 \pm 0.048$ & ND & $0.172 \pm 0.036$ \\
Soil & $0.015 \pm 0.005$ & $0.373 \pm 0.018$ & ND & $0.509 \pm 0.081$ \\
T. triangulare & $0.002 \pm 0.001$ & $0.108 \pm 0.024$ & ND & $0.195 \pm 0.048$ \\
Soil & $0.005 \pm 0.003$ & $0.434 \pm 0.046$ & ND & $0.523 \pm 0.074$ \\
T. occidentalis & $0.004 \pm 0.002$ & $0.125 \pm 0.024$ & ND & $0.158 \pm 0.057$ \\
Soil & $0.009 \pm 0.003$ & $0.340 \pm 0.027$ & ND & $0.606 \pm 0.084$ \\
V. amygdalina & $0.004 \pm 0.002$ & $0.188 \pm 0.023$ & ND & $0.383 \pm 0.118$ \\
Soil & $0.008 \pm 0.003$ & $0.475 \pm 0.005$ & ND & $1.030 \pm 0.120$ \\
\hline \multicolumn{4}{r}{ Values reported in mean } & SD format, ND - Not Detected
\end{tabular}

Values reported in mean $\pm S D$ format, $N D-$ Not Detected.

Table 2: Average level of $\mathrm{Cd}, \mathrm{Co}, \mathrm{Pb}$ and $\mathrm{Zn}$ in $\mathrm{mgkg}^{-1}$ (dry weight) in the soil and vegetables during the dry season in Yala urban area.

\begin{tabular}{llllc}
\hline Vegetable & Cd & Co & Pb & Zn \\
\hline Amarathus spp. & $0.003 \pm 0.002$ & $0.170 \pm 0.050$ & ND & $0.203 \pm 0.089$ \\
Soil & $0.008 \pm 0.003$ & $0.421 \pm 0.063$ & ND & $0.432 \pm 0.103$ \\
C. olitorius & $0.007 \pm 0.003$ & $0.195 \pm 0.080$ & ND & $0.217 \pm 0.094$ \\
Soil & $0.019 \pm 0.005$ & $0.454 \pm 0.050$ & ND & $0.905 \pm 0.100$ \\
M. koenigii & $0.006 \pm 0.003$ & $0.048 \pm 0.020$ & ND & $0.232 \pm 0.064$ \\
Soil & $0.015 \pm 0.004$ & $0.163 \pm 0.018$ & ND & $0.730 \pm 0.079$ \\
O. grattissimum & $0.002 \pm 0.001$ & $0.168 \pm 0.039$ & ND & $0.179 \pm 0.080$ \\
Soil & $0.005 \pm 0.003$ & $0.403 \pm 0.029$ & ND & $0.550 \pm 0.117$ \\
S. melongena & $0.006 \pm 0.003$ & $0.145 \pm 0.050$ & ND & $0.169 \pm 0.039$ \\
Soil & $0.014 \pm 0.005$ & $0.370 \pm 0.020$ & ND & $0.507 \pm 0.082$ \\
T. triangulare & $0.001 \pm 0.001$ & $0.105 \pm 0.038$ & ND & $0.189 \pm 0.053$ \\
Soil & $0.004 \pm 0.002$ & $0.430 \pm 0.040$ & ND & $0.519 \pm 0.079$ \\
T. occidentalis & $0.003 \pm 0.001$ & $0.122 \pm 0.028$ & ND & $0.156 \pm 0.059$ \\
Soil & $0.008 \pm 0.002$ & $0.338 \pm 0.029$ & ND & $0.602 \pm 0.081$ \\
V. amygdalina & $0.003 \pm 0.001$ & $0.183 \pm 0.027$ & ND & $0.380 \pm 0.119$ \\
Soil & $0.007 \pm 0.003$ & $0.472 \pm 0.026$ & ND & $1.027 \pm 0.021$ \\
\hline & ND- Not Detected, Values in mean \pm SD format
\end{tabular}

Several researchers have reported that the solubility of the cationic forms of the metals in the soil solution increases as the soil $\mathrm{pH}$ decreases, and they become readily available for plants to accumulate. For example, cadmium is more available at low soil $\mathrm{pH}$ (acidic soils) than neutral or alkaline soils (Filius et al., 1998, Mann and Ritche (1995) and Oliver et al., 1998). Mercury also is more bioavailable in acidic or low $\mathrm{pH}$ soils than alkaline soils (Melgar et al., 2009). Thus, acidic soils enhance the accumulation of metals by vegetables than neutral or alkaline soils. From the results, the soil $\mathrm{pH}$ ranged 4.2-6.8 indicating that the soil is quite acidic and should support the accumulation of these metals. This $\mathrm{pH}$ results agreed with an earlier study on the soil properties it was reported that 'the soil is porous, leached and its $\mathrm{pH}$ ranged from 4 to 6 (Free Library, 2014).' The results also indicate that there is no significant difference between the concentration of metals in the soil and that accumulated by the vegetables in the rainy and dry season of the year. However, the concentration of Cadmium, Cobalt and Zinc in the soil and that accumulated by the edible vegetables is still very low and within the permissible limits of WHO/FAO. Besides, Lead was not detected in the soil or the vegetables. Therefore efforts has to be made by relevant government agencies to maintain this low concentration of the metals in the study area through public awareness of the effects of pollution and a periodic environmental monitoring and assessment of the metals concentration in the area.

Table 3: Target Hazard Quotients of $\mathrm{Cd}, \mathrm{Co}, \mathrm{Pb}$ and $\mathrm{Zn}$ in Yala

\begin{tabular}{lllll}
\multicolumn{5}{c}{ Urban area in rainy season. } \\
\hline Vegetable & Cd & Co & Pb & Zn \\
\hline Amaranthus spp. & 0.0061 & 0.0027 & Nil & 0.0011 \\
C. olitorius & 0.0139 & 0.0031 & Nil & 0.0011 \\
M. koenigii & 0.0108 & 0.0008 & Nil & 0.0012 \\
O. grattissimum & 0.0031 & 0.0026 & Nil & 0.0009 \\
S. melongena & 0.0108 & 0.0023 & Nil & 0.0009 \\
T. triangulare & 0.0031 & 0.0017 & Nil & 0.0010 \\
T. occidentalis & 0.0061 & 0.0019 & Nil & 0.0008 \\
V. amygdalina & 0.0061 & 0.0029 & Nil & 0.0020 \\
\hline \multicolumn{4}{c}{ Note: Pb was not detected and has no THQ values. }
\end{tabular}

Table 4: Target Hazard Quotients of $\mathrm{Cd}, \mathrm{Co}, \mathrm{Pb}$ and $\mathrm{Zn}$ in Yala

\begin{tabular}{lllll}
\multicolumn{5}{c}{ Urban area in dry season } \\
\hline Vegetable & Cd & Co & Pb & Zn \\
\hline Amaranthus spp. & 0.0046 & 0.0026 & $\mathrm{Nil}$ & 0.0010 \\
C. olitorius & 0.0108 & 0.0030 & $\mathrm{Nil}$ & 0.0011 \\
M. koenigii & 0.0092 & 0.0007 & $\mathrm{Nil}$ & 0.0012 \\
O. grattissimum & 0.0031 & 0.0026 & $\mathrm{Nil}$ & 0.0009 \\
S. melongena & 0.0092 & 0.0022 & $\mathrm{Nil}$ & 0.0009 \\
T. triangulare & 0.0015 & 0.0016 & $\mathrm{Nil}$ & 0.0009 \\
T. occidentalis & 0.0046 & 0.0019 & $\mathrm{Nil}$ & 0.0008 \\
V. amygdalina & 0.0046 & 0.0028 & $\mathrm{Nil}$ & 0.0020 \\
\hline
\end{tabular}
Note: $P b$ was not detected and has no THQ values. 
Target hazard quotients (THQ) of the metals as shown in Tables 3 and 4 for $\mathrm{Cd}$, Co and $\mathrm{Zn}$ that were detected in the vegetables were far less than 1 for all vegetables in both seasons. This implies that the heavy metals concentration in the edible vegetables is not posing any risk and there is no potential health risk associated with their consumption for now. According to USEPA/IRIS (IRIS, 2011), 'it is only THQ values greater than 1 that shows there is potential health risk associated with the consumption of food or vegetables contaminated with a certain pollutant or heavy metal.' Thus, the THQ values also agreed with the fact that the mean concentrations of these metals in the vegetables are still low and within the permissible limits of $\mathrm{WHO} / \mathrm{FAO}$.

Conclusion: This study revealed that there is some amount of Cadmium, Cobalt and Zinc in the soil, which has been accumulated by the edible vegetables in the area. Lead was not detected in the area and seems negligible at the moment. The amount of the metals present in the soil and vegetable are still very low and within the permissible limits of WHO/FAO. Thus, the amount of these metals in the edible vegetables within the period of this study may not pose any health risk.

\section{REFERENCES}

Akan, JC; Abdulrahaman, FI; Sodipo, OA; Lange, AG (2010). Physicochemical parameter in soil and vegetable samples from Gongalon agricultural site, Maiduguri, Borno State, Nigeria. J. Amer. Sci. 12:78-88.

Akpe, MA; Ashishie, PB; Inezi, FP (2019). Health risk assessment of heavy metals ( $\mathrm{Cr}, \mathrm{Fe}, \mathrm{Hg} \& \mathrm{Ni})$ in edible vegetables in Yala urban area, Cross River State, Nigeria. Int. Res. J. Pure \& Appl. Chem. 19(2): 1-7.

Álvarez-Ayuso, E; Giménez, A; Ballesteros, JC (2011). Fluoride accumulation by plants grown in acid soils amended with flue gas desulphurisation gypsum. J. Hazardous Mat. 192(3): 1659 1666.

ATSDR (2010). Agency for Toxic Substances and Disease Registry (ATSDR). Draft Toxicology profile for Cobalt. Atlanta, G.A.

Dauguet, S; Denaix, L; Nguyen, C; Royer, E; Levasseur, P; Potin, G (2011). Mesure des flux d'éléments traces $(\mathrm{Pb}, \mathrm{Cd}, \mathrm{As}, \mathrm{Cu}, \mathrm{Zn})$ dans les sols, végétaux, porcs et lisiers des exploitations porcines du Sud -ouest. Innov. Agronomiques. 17:175-190. (French).

Dmello, JPF (2003). Food safety: Contaminants and toxins. Cambridge M.A., (AB) Publishing, Walling Ford, Oxon, U.K.
Emsley, J (2001). Nature's building blocks. An A-Z guide to the elements. Oxford University Press, Oxford, UK.

Filius, A; Streck, T; Retcher, J (1998). Cadmium sorption and desorption in limed top soils as influenced by $\mathrm{P}^{\mathrm{H}}$ : Isotherms and simulated leaching. J. Environ. Qual. 27:12-18.

Free Library (2014). Mineralogy and geochemical properties of some upland soils from different sedimentary formations in South-eastern Nigeria. www.thefreelibrary.com (Accessed July, 2015).

Fujimaki Hayacibara, M; Queiroz, CS; Machado Tabchoury, CP; Aparecido Cury, J (2004). Fluoride and aluminum in teas and tea-based beverages. Revista de Saude Publica, 38(1): 100105.

Halwell, B (2007). Critical Issue Report: still no free lunch. The organic center. Available at: www.organi-center.org. (Accessed July, 2014).

Harrison, N. (2001). Inorganic contaminants in food, In: Watson, D.H. (ed) Food Chemical Safety Contaminants. Woodhead Publishing Ltd., Cambridge, pp.148-168.

IRIS (2011). Integrated Risk Information System database. US Environmental Protection Agency (USEPA), USA.

Jackson, AP; Alloway, BJ (1993). The transfer of cadmium from agricultural soil to human food chain, In: D.C. Adriano (ed) Biogeochemistry of heavy metals. Levis Publishing, F.L.B Raton, p. 47.

Kiekens, L (1990). Zinc. In: Alloway, BJ (ed) Heavy metals in soils. John Wiley \& Sons, New York, p.78.

Kumar, R; Agrawal, M; Marshal, F (2007). Heavy metal contamination of soil and vegetables in suburban areas of Varanasi, India. Ecotoxic. \& Environ. Safe. 66(2): 258-266.

Mann, SS; Ritche, GSP (1995). Form of cadmium in sandy soils after amendment with soils of higher fixing capacity. Soil Sci. \& Plant Nutri. 87: 23-29.

Melgar, M.J; Alonso, J; Garcia, MA (2009). Mercury in edible mushrooms and underlying soil: Bioaccumulation factors and toxicological risk. Sci. Total Environ. 407(20):5328-5334.

Ming-Ho, Y. (2005). Environmental Toxicology: Biological and health effects of pollutants. CRC Press, BocaRaton, USA. 
Ndukwu, BC; Obute, GC; Eze, E (2008). Uptake and accumulation of heavy metals by plants on abandon refuse dumpsites in parts of River State, Nigeria. Scientia Africana, 7: 130-140.

Obasi, NA; Akubugwo, EI; Ugborgu, OC; Otuchristian, G (2012). Asseesment of physicchemical properties and heavy metals bioavailability in dumpsites along EnuguPort Harcourt expressway, South-east Nigeria. Asian J. Appl. Sci. 5: 342-356.

Oliver, DP; Tiller, KG; Alston, AM; Cozens, GD; Merry, RH (1998). Effects of soil PH and applied cadmium on cadmium concentration in wheat grain. Austral. J. Soil Res. 36: 571-583.

Rahman, MA; Rahman, MM; Reichman, SM; Lim, RP; Naidu, R (2014). Heavy metals in Australian grown and imported rice and vegetables on sale in Australia: Health hazard. J. Ecotoxic. Environ. Safe. 100: 53-60
Rattan, RK; Datta, SP; Chonkar. PK; Suribabu, K; Singh, AK (2005). Long term impact of irrigation with sewage effluents on heavy metals content in soil, crops and ground water, a case study. Agric. Ecosyst. Environ. 109: 310-322.

Salama, A; Radwan, M (2005). Heavy Metals (Cd, Pb) and Trace Elements $(\mathrm{Cu}, \mathrm{Zn})$ Contents in Some Foodstuffs from Egyptian Market. Emir. J. Agric. Sci.17 (1):34-42.

Shuman, LM (1991). Micronutrients in agriculture. In: Madison, WI (ed) Chemical forms of micronutrients in soils. Soil science society of America, SSSA Book Series, USA, pp. 113-114.

Suruchi, S; Khanna, P (2011). Assessment of heavy metal contamination in different vegetables grown in and around urban areas. Res. J. Environ. Toxic. 5: 162-179.

Tan, Z; Xiao, G (2012). Leaching characteristics of fly ash from Chinese medical waste incineration, Waste Manage. Res. 30(3): 285-294. 